nare al proprio pubblico» (p. 343). Non essendo praticabile una riscrittura degli eventi biografici precocemente affidati alla Commedia, poiché il poema sta già circolando, Dante tenta un difficile accordo tra l'autobiografia profetica e quella, originaria, di conversione. Non tutto può quadrare: se il nuovo atteggiamento di Beatrice dopo l'incontro con Cacciaguida non crea «increspature evidenti» sulla superficie del poema (p. 345), e se l'investitura dell'avo consente la piena affermazione dell'autobiografia fiorentina sul modello alternativo dell' $i$ ter di affrancamento dal peccato (di cui questa era originariamente parte), non si annulla la discontinuità ideologica con l'impianto «scritturale, fortemente in debito con i libri profetici» dei primi canti dell, Inferno (p. 346-347). Ma i due paradigmi dissonanti, quello del peccatore in via di conversione e quello del profeta perseguitato, non coabitano solo in Dante: Brilli chiude il suo lavoro ricordando l'analogo meccanismo messo in atto nell' Historia calamitatum di Pietro Albelardo (p. 347-349) e -riscontro notevolissimo- nell'Iconologia overo

\section{La Veneciana}

Madrid: Cátedra, 2013, 158 p. ISBN: 978-84-376-3086-1

Cesáreo Calvo Rigual y Anna Giordano Gramegna editan por primera vez en español La Venexiana, una comedia anónima escrita, según afirma gran parte de la crítica, entre 1535 y 1537 , derivada quizás de un suceso real, y ambientada en una Venecia descrita con minucioso realismo. La comedia se inserta en la corriente del teatro humanista que germinaba y se extendía con pujanza en la Venecia del Renacimiento. Nuevas for-
Descrittione dell'imagini universali cavate dall'antichità et da altri luoghi dell'accademico degli Intronati Cesare Ripa, morto nel 1622 (!). Qui, alla voce esilio, la dualità pubblico/privato è vertiginosamente sintetizzata nella medesima categoria: esiliato è sia il condannato all'espulsione dal potere politico che il viandante diretto a Santiago a scopo penitenziale (p. 349-351). Tra il pellegrino convertito e il giusto perseguitato la cultura dell'Occidente medievale ha dunque riconosciuto un'affinità: e in fondo, se la civitas diaboli è al contempo la $c a-$ terva impiorum e il saeculum umano, l'allontanamento da essa può leggersi come processo di affrancamento dal peccato e, senza che la dissonanza diventi contraddizione, come riconoscimento di un'investitura profetica (p. 352-354). Ciò dimostra, in definitiva, il percorso di Dante; e ciò illustra, con felicità di pensiero e scrittura, lo studio di Elisa Brilli.

Luca Fiorentini

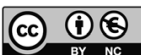

mas teatrales que se desarrollaron desde un plano popular y dialectal con la intención de enseñar y divertir, y que generaron un teatro abierto a la innovación y a la experimentación literaria.

Venecia se presenta, en aquellos años, como un importante centro urbano expuesto a un cosmopolitismo profuso que oxigena de manera constante los usos y costumbres de la vida pública y privada de sus ciudadanos. Y es esta renovación 
permanente la que determina las tendencias y el carácter de la actividad teatral que se extiende por toda la ciudad. La alta burguesía veneciana adopta un aspecto señorial y, con el deseo de imitar los fastos aristocráticos, genera una literatura que, si bien se rige por los mismos principios de buen gusto y cortesía que dictaminan la razón de ser de la literatura áulica, presenta un tono completamente distinto de los modales palaciegos. Los autores burgueses son cultos, pero escriben con el descanso de no tener que reverenciar a los clásicos. Rechazan los aderezos sentimentales y estilísticos del repertorio clasicista, amén de las muestras de intelectualismo que inflaban las comedias con que se deleitaban los señores de la corte.

Debido al tráfago no sólo de mercancías, sino de ideas y pareceres diversos, no es de extrañar que Venecia viviera enfrentada con otros centros de poder de la península italiana, como Florencia, donde se estaba llevando a cabo un exhaustivo proceso regularizador del teatro en aras de una actividad comercial y teatral sustancialmente más limitadas que las de la ciudad del Gran Canal. Así, los textos venecianos no asumen rigurosamente la herencia clásica, aunque nunca abandonan el trasfondo de ésta, y presentan una naturaleza anfibia que no los adscribe a géneros concretos. Textos destinados a ser recitados y representados que tratan de reproducir con naturalidad y viveza la conducta de los ciudadanos. En la Venecia abierta al mundo conviven y se influyen mutuamente la disparidad de formas burguesas y la observancia cortesana donde perduran los usos de la comedia latina y las reglas aristotélicas con una presencia relativamente firme.

La edición bilingüe de Calvo Rigual y Giordano Gramegna, en Cátedra, nos sitúa la comedia en este contexto teatral del que nos ofrece una visión panorámica, pero precisa. Es esta edición una auténtica oportunidad para conocer las coordenadas literarias y sociales en que se incardina esta espléndida comedia cuyo único manuscrito conservado descubrió y transcribió Emilio Lovarini en la Biblioteca Marciana de Venecia en 1928. Una comedia escrita en prosa y dividida en cinco actos donde el respeto a las tres unidades aristotélicas es relativo y el verismo y la belleza de los diálogos son extraordinariamente inusuales. Así, los editores, en su introducción, recorren los aspectos necesarios y fundamentales para conocer la obra, en qué condiciones se gestó y su recepción por parte de la crítica. Y lo hacen aportando información concisa, pero con una clara voluntad pedagógica que acerca al lector todo un panorama crítico y literario denso y complejo.

De este modo, nos facilitan las diferentes tesis que hay acerca de la autoría de la comedia. Para Lovarini, el autor sería Girolamo Fracastoro, autor del poema Syphilis. Giorgio Padoan, en cambio, apunta que sería otro Girolamo, Zarotto, no el que escribiera, sino el que copiara la obra, pues así lo revelan algunos errores de copia difícilmente atribuibles al autor. No cabe duda, por su parte, de que el autor era una persona con una sólida cultura que se sigue de las acotaciones, los nombres de los personajes, el Colophon latino y el prólogo de la comedia, de ascendencia clásica y escrito en italiano áulico. Otro aspecto sujeto a discrepancias es la fecha de composición. Padoan asegura que, según indicios presentes en la obra, la comedia se compuso en el año 1536. Linda Carrol, por su parte, retoma la tesis de Lovarini fija 1519 como año de composición.

A pesar de estos desacuerdos, todos coinciden en inscribir la comedia en la corriente del teatro humanista que estaba en auge en aquellos años, según lo que apunta Ireneo Sanesi. Y es que la pluralidad de la experiencia teatral en Venecia estaba garantizada por la existencia de numerosas asociaciones urbanas que, 
como en Florencia, producían numerosos espectáculos desde la primera mitad del siglo xv. En Venecia, fueron especialmente importantes las denominadas Compagnie della Calza, un conjunto de grupos elitistas compuestos por jóvenes aristócratas que buscaban divertirse y participar públicamente en la vida teatral veneciana. Fue en el seno de alguno de estos círculos donde se compuso y se representó (quizás en orden inverso) La Veneixana.

La comedia en cuestión retrata con maestría y con un carácter eminentemente narrativo el furor y la pasión que dos mujeres de la alta sociedad veneciana sienten por Julio, un joven extranjero que arriba a la ciudad con el único deseo de medrar a costa de poner en entredicho su propia honra. Julio, al llegar a Venecia, se enamora de Valeria, y después de un breve cortejo, ésta cita al joven lombardo para encontrarse con él por la noche. Pero la viuda Ángela, presa de pasión por Julio, gracias a la mediación de Bernardo, mozo de cuerda bergamasco, engaña al joven y hace que se lo traigan a casa. El joven cede a la pasión amorosa de la viuda. Después de este encuentro nocturno, Julio es obligado a soportar la rabia celosa de Valeria, la cual, no obstante, víctima de la fuerza de amor, perdona inmediatamente al muchacho y se entrega a él. Ambas damas, Valeria y Ángela muestran muy a las claras, y según expone el autor de la comedia en el prólogo, "cuán patente es el Amor en la mujer y de qué manera somos vencidos por su fuerza».

El tratamiento desenfadado de la materia amorosa que se da en la comedia está influenciado por Aretino. La obra, además, presenta una polifonía de lenguas característica del teatro popular de aquellos años: al italiano áulico del autor y del joven Julio, se le unen el veneciano de las damas y sus doncellas y el bergamasco de Bernardo, el mozo de cuerda y, a la sazón, gondolero, sin olvidar el latín con que aparece la lista de personajes y la moraleja final.

Cesáreo Calvo Rigual y Anna Giordano Gramegna nos ofrecen cabalmente estos y otros tantos datos esenciales para leer con perspectiva y buen sentido la comedia. Para su edición, toman como texto base el que ya fijara Ludovico Zorzi en 1965, además de sus acotaciones, imprescindibles para entender el movimiento escénico, y la división en escenas, que se aleja de la que ofrece Giorgio Padoan en su edición de 1974. Tampoco añaden las siete poesías, de distintos autores, que aparecen en el manuscrito y que con seguridad se cantaban en determinados momentos de la representación de la comedia. Es importante señalar, además, que en la introducción de esta esperada primera edición en español de la comedia veneciana, se añade un interesante apartado en que se estudian comparativamente la comedia que nos ocupa, La viuda valenciana, de Lope de Vega, y un cuento de Mateo Bandello. Sin duda, una muestra más del afán esclarecedor y del buen hacer de sus editores.

Julio Ángel Ruiz González-Calero 